ORPHAN LUNG DISEASE

\title{
Survival and disease progression in UK patients with lymphangioleiomyomatosis
}

\author{
S R Johnson, C I Whale, R B Hubbard, S A Lewis, A E Tattersfield
}

Thorax 2004;59:800-803. doi: 10.1136/thx.2004.023283

See end of article for authors' affiliations

......................

Correspondence to:

Dr S R Johnson, Division of

Therapeutics and

Molecular Medicine,

Queens Medical Centre,

University of Nottingham

Nottingham NG7 2UH,

UK; simon.johnson@

nottingham.ac.uk

Received

13 February 2004

Accepted 3 May 2004
Background: Lymphangioleiomyomatosis (LAM) is a rare and progressive disease of young women with no effective treatment. Previous estimates of 10 year survival, based mostly on case series or patients from tertiary centres, have ranged from $40 \%$ to $79 \%$; no data are available on the progression of respiratory disability. In order to provide data for patients and for planning intervention studies, we have looked at the time course of LAM using a national cohort.

Methods: Time to death, time to MRC dyspnoea grades 2-5, and need for oxygen in patients on the UK LAM database were analysed using Kaplan-Meier analysis and Cox regression.

Results: Fifty seven of 72 patients responded with a median duration of follow up of 12.6 years (range 2.3-37) from the onset of symptoms. Ten year survival was $91 \%$ from onset of symptoms but varied widely with 11 patients alive after 20 years. Median time to MRC grade 3 dyspnoea (breathless walking on the flat) was 9.3 years $(95 \% \mathrm{Cl} 5.1$ to 13.4$)$ from onset of symptoms.

Conclusions: Survival from LAM appears to be better than that reported in early studies. These data should be helpful for patients and for planning clinical trials. ymphangioleiomyomatosis (LAM) is a progressive disease of young women which usually causes death from -respiratory failure. Infiltration of the lungs and axial lymphatics by LAM cells, an unusual form of smooth muscle cell, results in cystic lung disease, recurrent pneumothorax, and chylous collections in the thorax and abdomen. ${ }^{1}$ Sporadic LAM affects about one per million of the UK population, ${ }^{2}$ although the disease can also occur as part of the tuberous sclerosis complex. LAM is thought to progress more rapidly in the presence of high oestrogen levels and may be treated with progesterone. $^{3}$

Initial reports of sporadic LAM based on case reports and necropsy series of patients suggested that survival was usually less than 10 years from the onset of symptoms. ${ }^{45}$ Survival has been better in more recent series with many or most patients living for 10 years or more. ${ }^{6-8}$ These studies have used different methods to identify patients and it is unclear to what extent the patients studied represent the full spectrum of those with LAM. To provide data on the longer term prognosis for patients with LAM, we studied survival and disease progression in patients from the UK national LAM database. We also looked at the effect of various factors such as cigarette smoking on disease progression.

\section{METHODS}

\section{Patients and data collection}

Patients enrolled on the UK LAM register following its inception in 1995 were studied. We have tried to identify all patients with LAM in the UK, initially by writing to chest physicians, pathologists and surgeons and subsequently recruiting new patients by word of mouth and through the LAM Action website (http://www.LAMaction.org) and the British Thoracic Society Orphan Lung Disease database (BOLD). At the time of the study the LAM database comprised 76 patients including both prevalent patients from 1995 and incident cases arising thereafter. Patients are accepted onto the database on the basis of a physician made diagnosis of LAM, and they are then asked whether in principle they are willing to participate in research in the future. Patients who had agreed to help with research $(\mathrm{n}=72$ ) were contacted by letter, invited to participate in the study, and informed consent was obtained. Some of the patients included in this study have contributed to previous studies by our group. ${ }^{2}{ }^{10}$

Patients completed a proforma concerning presenting symptoms of LAM and the dates when symptoms relating to the five points on the MRC dyspnoea scale ${ }^{11}$ had occurred (table 1), or when home oxygen was prescribed. Details of contraceptive pill use, hormonal treatment for LAM, cigarette smoking, and pregnancy were also obtained. When a patient on the database had died, details were collected from hospital notes. The study was approved by Nottingham local research ethics committee and the LAM database by Trent multicentre research ethics committee.

\section{Analysis of data}

Survival at 10 years (including survival after lung transplantation) was calculated by Kaplan-Meier analysis from the onset of symptoms of LAM. Disability was calculated as time to increasing dyspnoea as judged by the five points on the MRC dyspnoea scale and time to the provision of home oxygen using Kaplan-Meier analysis. The effects of presenting symptoms, use of the oral contraceptive pill, age at first symptom, cigarette smoking, pregnancy, and use of

Table 1 MRC dyspnoea scale

\begin{tabular}{ll}
\hline Statement & $\begin{array}{l}\text { MRC dyspnoea } \\
\text { grade }\end{array}$ \\
\hline $\begin{array}{l}\text { I only get breathless after strenuous exercise } \\
\text { I get short of breath when hurrying on the } \\
\text { level or on a slight hill }\end{array}$ & 1 \\
I walk slower than people of the same & 2 \\
age on the level because of breathlessness or \\
have to stop for breath when walking at \\
$\begin{array}{l}\text { my own pace on the level } \\
\text { I have to stop for breath after walking } 100 \text { yards } \\
\text { or after a few minutes on the level }\end{array}$ & 4 \\
I am too breathless to leave the house & 5 \\
\hline
\end{tabular}



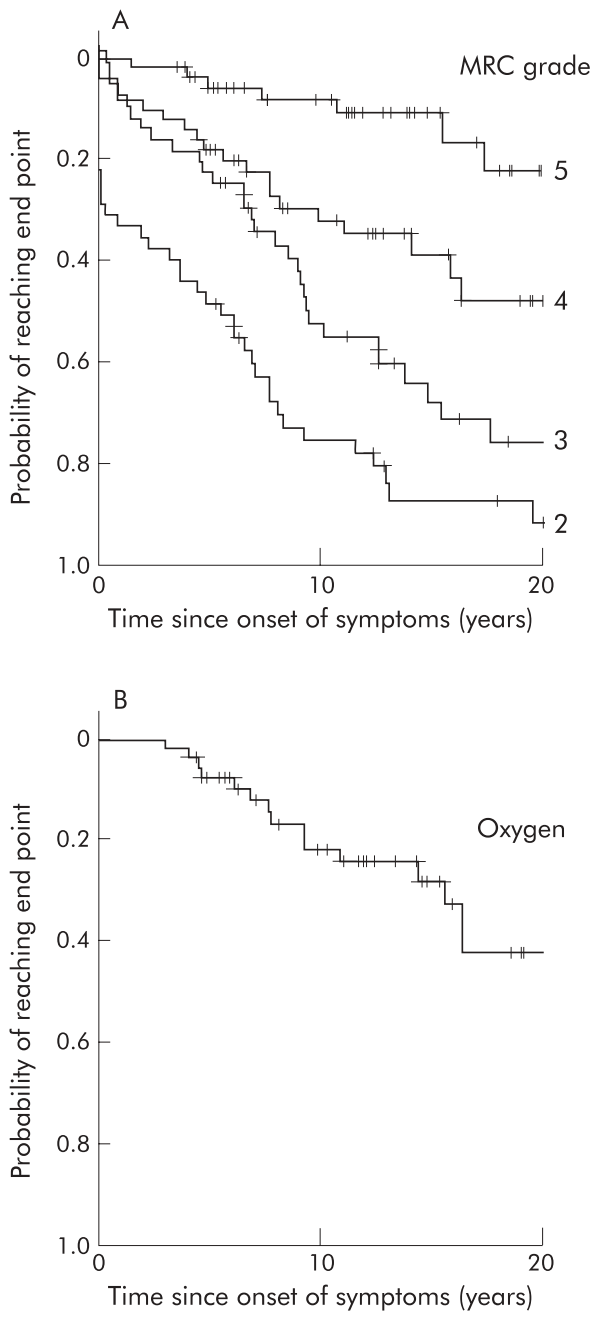

Figure 1 Kaplan-Meier plots of (A) time to MRC dyspnoea grades 2-5 and (B) time to provision of oxygen therapy. Cases who had not reached the end point before the time of writing are censored (shown as a cross). Plots are truncated at 20 years.

progesterone on disease progression were assessed by multivariate Cox regression. Since time to MRC grade 3 dyspnoea contained the largest number of events, it was used as the primary end point to assess factors associated with disease progression to increase statistical power. The same analysis was performed on time to MRC grade 4 dyspnoea to check the robustness of our findings. Statistical analysis was performed using SPSS (SPSS Inc, Chicago, IL, USA).

\section{RESULTS}

Details were obtained from 57 of the 72 patients, 53 who completed the questionnaire and four who had died for
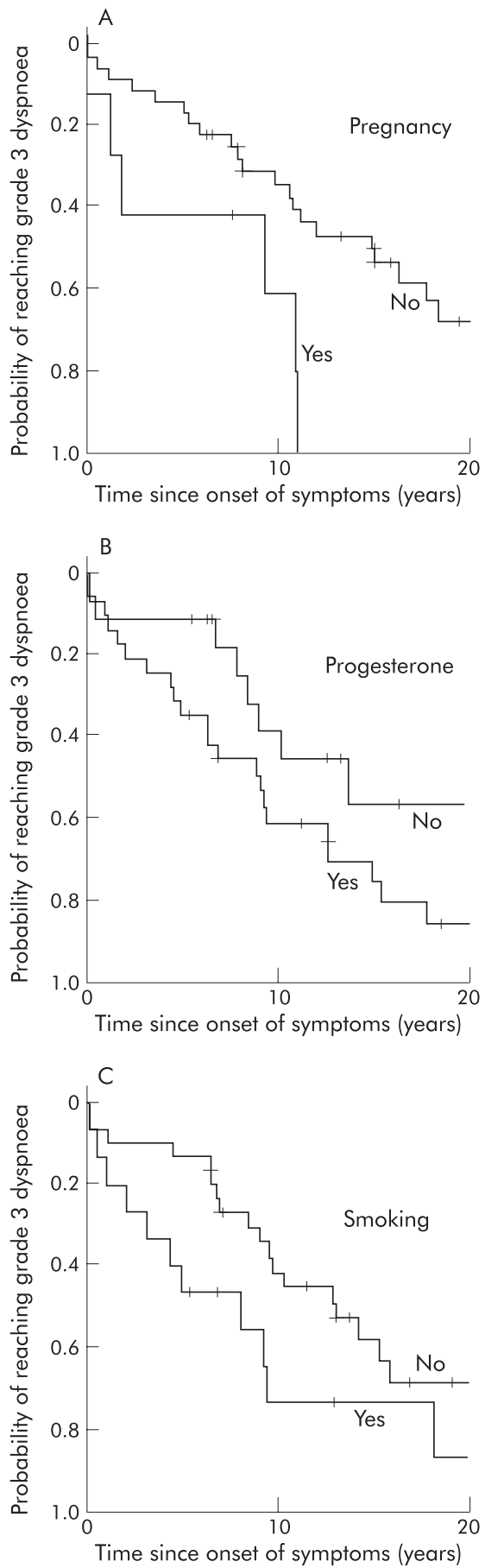

Figure 2 Effect of (A) pregnancy after the diagnosis of LAM, (B) use of progesterone therapy, and (C) ever having smoked on time to MRC grade 3 dyspnoea from onset of symptoms. Plots are truncated at 20 years.

Table 2 Median time (95\% confidence interval (CI)) in years from onset of symptoms to reaching MRC dyspnoea grades 2-5 and cumulative probability $(95 \% \mathrm{Cl})$ of reaching these end points at 5 and 10 years

\begin{tabular}{|c|c|c|c|c|c|}
\hline End point & $\mathbf{n}$ & Censored & Median time $(95 \% \mathrm{CI})$ & $\begin{array}{l}5 \text { year probability of reaching } \\
\text { end point }(95 \% \mathrm{Cl})\end{array}$ & $\begin{array}{l}10 \text { year probability of reaching } \\
\text { end point }(95 \% \mathrm{Cl})\end{array}$ \\
\hline MRC 2 & 47 & 7 & 5.7 (2.5 to 8.8$)$ & $0.49(0.35$ to 0.63$)$ & $0.75(0.61$ to 0.88$)$ \\
\hline MRC 3 & 47 & 15 & $9.3(5.1$ to 13.4$)$ & $0.25(0.13$ to 0.38$)$ & 0.55 (0.40 to 0.70$)$ \\
\hline MRC 4 & 52 & 32 & $\mathrm{NA}^{*}$ & $0.19(0.09$ to 0.30$)$ & 0.31 (0.18 to 0.44$)$ \\
\hline MRC 5 & 56 & 48 & $\mathrm{NA}^{*}$ & $0.04(0$ to 0.08$)$ & $0.10(0.02$ to 0.18$)$ \\
\hline Home oxygen & 56 & 39 & $\mathrm{NA}^{*}$ & $0.05(0$ to 0.11$)$ & $0.23(0.11$ to 0.35$)$ \\
\hline
\end{tabular}


whom a questionnaire was completed from hospital notes (overall response rate $79 \%$ ). Data on disability were not available for one patient who had died but her death was included in the survival analysis. Thirteen of the 15 patients who did not complete the questionnaire were known to be alive, while in two cases there was no response from the patient or physician. Twenty two of the 57 patients were incident cases diagnosed since 1995 and 35 were prevalent cases. The total follow up was 718 person years from the onset of symptoms (median 12.6 per patient (range 2.3$37.4)$ ) and 416 person years from the date of joining the LAM database (median 7.3 per patient (range 2.3-8.0)). The patients were all female with a mean age at onset of symptoms of 33.6 years. Fifty six were white and one was of Asian ethnic origin. The presenting symptoms were dyspnoea $(47 \%)$, pneumothorax (37\%), chylous pleural effusion $(7 \%)$, haemoptysis $(5 \%)$, and other symptoms $(4 \%)$. The diagnosis had been made by lung biopsy in 43 patients, CT scan plus the presence of an angiomyolipoma or chylous effusion in three patients, extrapulmonary tissue biopsy plus CT scan in one patient, and CT scan alone in eight patients. Two patients were thought to have tuberous sclerosis although their major clinical manifestation was LAM. Thirty six patients had received hormone treatment for LAM, 34 with progesterone alone, one with progesterone and tamoxifen, and one with progesterone and a gonadotrophin releasing hormone analogue.

Over the period of observation five of the 57 patients had died (one following lung transplantation) and six were alive following a lung transplant. The overall survival probability in this group at 10 years from the onset of symptoms was 0.91 (95\% CI 0.83 to 0.99 ). Twenty one patients had been observed for 15 years or more, 18 of whom were still alive, and 12 had been observed for 20 years or more of whom 11 were still alive.

The time at which patients reached dyspnoea grades $2-5$ and the time to the provision of home oxygen are shown in table 2 and fig 1 . Few patients could clearly recall when they had reached MRC dyspnoea grade 1 and these data are not presented. From the onset of symptoms the median time to MRC grade 2 was 5.7 years (95\% CI 2.5 to 8.8 ) and to grade 3 was 9.3 years (95\% CI 5.1 to 13.4 ).

\section{Factors affecting disease progression}

Although there was more rapid progression to MRC grade 3 dyspnoea in cigarette smokers (hazard ratio 2.0 (95\% CI 0.9 to 4.3$)$ ), those who had been pregnant after the onset of symptoms (2.7 (95\% CI 1.0 to 7.4$))$ and patients treated with progesterone $(2.2$ (95\% CI 1.0 to 4.9$))$ were all of borderline statistical significance at the 5\% level (table 3, fig 2). Age at onset of symptoms and use of the contraceptive pill had no effect on time to MRC grade 3 dyspnoea (table 3 ). Although the numbers were smaller, the hazard ratios for time to MRC dyspnoea grade 4 were similar to those for MRC grade 3 (pregnancy: 1.8 (95\% CI 0.5 to 6.5 ), contraceptive pill use: 0.9 (95\% CI 0.3 to 2.4), age at onset under 33: 0.5 (95\% CI 0.2 to 1.3 ), progesterone treatment: 6.5 (95\% CI 1.5 to 28.5), cigarette smoking: 2.1 (95\% CI 0.8 to 5.3)). The presenting symptom had no effect on either end point (data not shown). When all the variables were entered in a multivariate Cox regression model, there was no substantial change in either the size or statistical significance of the hazard ratios.

\section{DISCUSSION}

We set out to provide information on the prognosis for patients with LAM. Ten years after the onset of symptoms $55 \%$ of our cohort had developed MRC grade 3 dyspnoea, $23 \%$ were taking oxygen treatment, and $9 \%$ had died. Survival varied considerably between patients, however, with several alive after 15 years or more as noted previously. $^{212}$

To minimise selection bias we tried to include all patients with LAM in the UK. Nevertheless, our figures are based in part on prevalent cases from 1995 and hence are subject to survival bias since those who die rapidly would be underrepresented in this cohort. Given the low incidence of LAM, however, studies based on incident cases alone are not yet feasible. Our 10 year survival estimate of $91 \%$ compares with figures of $40 \%^{7}$ and $70 \%$ in previous studies of prevalent cases. ${ }^{68}$ Improved diagnosis and treatment, including lung transplantation, may have contributed to longer survival.

We examined disability in our cohort since this should provide useful end points of disease progression. The MRC dyspnoea scale is a simple, well validated clinical index of dyspnoea $^{11}{ }^{13}$ and, with the exception of grade 1 (breathless after strenuous exercise), most patients were able to recall when they reached the different stages. Nine years after their first symptom of LAM half the patients had developed breathlessness to the level where they had to stop on the flat or walk more slowly than people of the same age (grade 3). Ten years from symptom onset $55 \%$ had reached grade 3 dyspnoea, $23 \%$ had been prescribed oxygen for use at home, and 10\% were housebound because of dyspnoea.

Previous studies suggested that age at onset of LAM and cigarette smoking had an adverse effect on outcome in LAM ${ }^{14}$ but we were unable to confirm these findings. Cigarette smokers reached grade 3 dyspnoea sooner than non-smokers

Table 3 Effect of various factors on the median time (years) for patients to reach MRC grade 3 dyspnoea from onset of symptoms

\begin{tabular}{|c|c|c|c|c|c|}
\hline & \multicolumn{2}{|l|}{ Yes } & \multicolumn{2}{|l|}{ No } & \multirow[b]{2}{*}{$\begin{array}{l}\text { Hazard ratio } \\
(95 \% \mathrm{Cl})\end{array}$} \\
\hline & n (censored) & $\begin{array}{l}\text { Median } \\
(95 \% \text { CI) }\end{array}$ & n (censored) & $\begin{array}{l}\text { Median } \\
(95 \% \mathrm{Cl})\end{array}$ & \\
\hline $\begin{array}{l}\text { Pregnancy since } \\
\text { diagnosis }\end{array}$ & $7(1)$ & $7.8\left(0.0^{*}\right.$ to 20.4$)$ & 38 (14) & 12.4 (7.4 to 17.5 ) & 2.7 (1.0 to 7.4$)$ \\
\hline Ever taken OCP & $34(11)$ & 9.0 (8.3 to 9.7 ) & $13(4)$ & 12.5 (2.9 to 13.75 ) & $1.2(0.5$ to 2.6$)$ \\
\hline $\begin{array}{l}\text { Age at onset } \\
\text { under } 33\end{array}$ & $25(6)$ & 9.3 (7.7 to 10.8$)$ & $21(8)$ & 8.8 (4.7 to 12.9$)$ & $1.0(0.5$ to 2.0$)$ \\
\hline $\begin{array}{l}\text { Ever had } \\
\text { progesterone } \\
\text { treatment }\end{array}$ & $29(6)$ & $9.0(5.5$ to 12.5$)$ & $18(9)$ & 13.6 (6.3 to 20.9$)$ & $2.2(1.0$ to 4.9$)$ \\
\hline Ever smoked & $15(4)$ & 7.8 (1.8 to 13.7$)$ & $30(10)$ & 12.5 (7.7 to 17.4$)$ & 2.0 (0.9 to 4.3$)$ \\
\hline
\end{tabular}

OCP, oral contraceptive pill.

Censored identifies patients who had not achieved grade 3 dyspnoea by end of follow up.

*Value of zero is due to one patient presenting with grade 3 dyspnoea. 
(hazard ratio 2.0), but this was not statistically significant Smoking habits were relatively modest, however, and only five of the 12 patients who had smoked had more than a 20 pack year smoking exposure. Pregnancy may have an adverse effect on $\mathrm{LAM}^{6}{ }^{15}$ and, although firm conclusions cannot be drawn from so few patients, the seven patients who became pregnant after developing LAM reached grade 3 dyspnoea 4 years earlier than those who had not become pregnant. These patients also had more complications from LAM during pregnancy, as discussed elsewhere. ${ }^{9}$ Progesterone, the most commonly used hormone treatment for LAM in the UK, was associated with a more rapid progression to grade 3 dyspnoea. We assume that this is because progesterone is more likely to be given to patients whose condition is deteriorating rapidly. In our previous retrospective study, patients treated with progesterone had lower baseline lung function than untreated patients but a trend towards a slower rate of decline in forced expiratory volume in 1 second with progesterone. ${ }^{2}$ Nevertheless, in the absence of a prospective trial, an adverse effect of progesterone treatment on LAM cannot be excluded.

Obtaining accurate and clinically useful data on survival of patients with a rare disease is difficult. The use of MRC dyspnoea grades allowed us to obtain useful clinical data, and such a strategy may be useful for other rare diseases. We tried to obtain data on all patients with LAM in the UK and our cohort should be reasonably representative of the spectrum of disease severity seen in patients with LAM, albeit with some bias towards the longer survivors. Our findings should be helpful in planning forthcoming trials of new treatments and should also be useful for patients with LAM.

\section{ACKNOWLEDGMENTS}

The authors are grateful to Jane Tallents and Jan Johnson for administrative support and running the LAM database, Jo Pounder for secretarial assistance, and the LAM patients for completing the questionnaires.

\section{Authors' affiliations}

S R Johnson, Division of Therapeutics and Molecular Medicine, University of Nottingham, Nottingham, UK

C I Whale, R B Hubbard, S A Lewis, A E Tattersfield, Division of Respiratory Medicine, University of Nottingham, Nottingham, UK

The study was funded by LAM Action UK.

\section{REFERENCES}

1 Johnson S. Rare diseases. 1. Lymphangioleiomyomatosis: clinical features, management and basic mechanisms, Thorax 1999;54:254-64.

2 Johnson SR, Tattersfield AE. Decline in lung function in lymphangioleiomyomatosis: relation to menopause and progesterone treatment. Am J Respir Crit Care Med 1999;160:628-33.

3 Sullivan EJ. Lymphangioleiomyomatosis: a review. Chest 1998;114:1689-703.

4 Corrin B, Liebow AA, Friedman PJ. Pulmonary lymphangioleiomyomatosis. Am J Pathol 1975;79:348-82.

5 Silverstein EF, Ellis K, Wolff M, et al. Pulmonary lymphangiomyomatosis. Am J Roentgen Rad Ther Nucl Med 1974;120:832-50.

6 Urban T, Lazor R, Lacronique J, et al. Pulmonary lymphangioleiomyomatosis. A study of 69 patients. Groupe d'Etudes et de Recherche sur les Maladies "Orphelines" Pulmonaires (GERM"O"P). Medicine (Baltimore) 1999;78:321-37.

7 Kitaichi $\mathrm{M}$, Nishimura K, Itoh $\mathrm{H}$, et al. Pulmonary lymphangioleiomyomatosis: a report of 46 patients including a clinicopathologic study of prognostic factors. Am J Respir Crit Care Med 1995;151:527-33.

8 Taylor JR, Ryu J, Colby TV, et al. Lymphangioleiomyomatosis. Clinical course in 32 patients. N Engl J Med 1990;323:1254-60.

9 Johnson SR, Tattersfield AE. Clinical experience of lymphangioleiomyomatosis in the UK. Thorax 2000;55:1052-7.

10 Whale CI, Johnson SR, Phillips KG, et al. Lymphangioleiomyomatosis: a casecontrol study of perinatal and early life events. Thorax 2003;58:979-82.

11 Fletcher CM. Standardised questionnaire on respiratory symptoms: a statement prepared and approved by the MRC Committee on the Aetiology of Chronic Bronchitis (MRC breathlessness score). BMJ 1960;2:1665.

12 Chu SC, Horiba K, Usuki J, et al. Comprehensive evaluation of 35 patients with lymphangioleiomyomatosis. Chest 1999;115:1041-52.

13 Bestall JC, Paul EA, Garrod R, et al. Usefulness of the Medical Research Council (MRC) dyspnoea scale as a measure of disability in patients with chronic obstructive pulmonary disease. Thorax 1999;54:581-6.

14 Lazor R, Lauque D, Deleval P, et al. Predictors of rapid decline of FEV1 in 50 cases of pulmonary lymphangioleiomyomatosis followed for $>1$ year (abstract). Am J Respir Crit Care Med 2000;161:A15.

15 McLoughlin L, Thomas G, Hasan K. Pregnancy and lymphangioleiomyomatosis: anaesthetic management. Int J Obstet Anesth 2003;12:40-4. 